Nhất năm 2018 với kết quả điều trị tốt 87,36\%.

\section{KẾT LUẬN}

- Tai nạn vào ban ngày là $57,4 \%$, ban đêm là $42,6 \%$. Phương tiện gây tai nạn phổ biến là mô tô $(81,7 \%)$; xảy ra tại thành thị $(63,3 \%)$ và nông thôn $(36,7 \%)$; Xét nghiệm có $25,2 \%$ bệnh nhân có cồn trong máu. Tỷ lệ chấn thương chi $(31,9 \%)$ và chấn thương đầu mặt cổ $(30,7 \%)$. Mức độ nặng các thương tích: nhẹ $(95,5 \%)$, trung bình (3,1\%), nặng $(1,4 \%)$.

- 36,9\% bệnh nhân được sơ cứu tại hiên trường, kỹ thuật sơ cứu không tốt chiếm $69,0 \%$. Bệnh nhân được sơ cứu đúng cách $(17,4 \%)$, không đúng cách $(82,6 \%)$. Đảm bảo an toàn khi vận chuyển là $51,0 \%$. Điều trị nội khoa chiếm tỷ lệ cao nhất $(43,6 \%)$, phẫu thuật cấp cứu $(14,5 \%)$. Kết quả điều trị khỏi $89,3 \%$, tử vong $0,5 \%$. Đánh giá kết quả điêu trị thành công $94,5 \%$, không thành công 5,5\%.

\section{TÀI LIÊU THAM KHẢO}

1. Bộ Giao thông vận tải (2020), An Giang: Tiếp tực thực hiện các giải pháp làm giảm số vụ tai nạn giao thông, Cổng thông tin điện tử Bộ giao thông vận tải.
2. Bộ Giao thông vận tải (2020), Hai tháng đầu nẳm, tai nạn giao thông giảm cả ba tiêu chí, . Cổng thông tin điên tử Bố giao thông vân tải.

3. Lê Bảo Huy, Lê Công Thuyên, Vố Ngọc Thông (2018), "Nhận xét đặc điêm ở bệnh nhân chấn thương tại Khoa cấp cứu Bệnh viện Thống Nhất". Tạp chí Y học TP. Hô Chí Minh, Số 3, tr. 244 - 247.

4. Hừynh Văn Hùng (2012), Nghiên cứu tình hình thương tích do tai nạn giao thông đường bộ đến khám và điều trị tai Bênh viên đa khoa Cà Mau, Luận án chuyên khoa cấp II, Trường Đại học Y Dược Cần Thơ.

5. Phạm Minh Khuê, Vũ Hải Vinh (2018), "Đánh giá công tác sơ cấp cứu nan nhân tai nạn giao thông đường bộ tại Bệnh viển Hữu Nghị Việt Tiệp năm 2018", Tạp chí Y học Việt Nam, tập 48, số 1, tr. $130-134$.

6. Nguyễn Trung Kiên (2020), Nghiên cứu tình hình chấn thương và đánh giá kết quả xứ trí cấp cứu bênh nhân bị tai nan giao thông tai Bênh viên 121 nẳm 2019 - 2020, Luận văn chuyền khoa cấp II Trường Đai hoc Y Dược Cần Thơ.

7. Phạm Thị Mỹ́ Ngọc (2012), Nghiên cứu tình hình sơ cứu bệnh nhân tai nạn giao thông đường bộ trước khi nhập viên Bệnh viện Đa khoa Trung ương Cần Thớ, Luận văn thạc sĩ Y tế công cộng, Trường Đai học Y Dược Cần Thớ.

8. Nguyễn Hữu Thuấn (2010), Nghiên cứu tình hình bệnh nhân tai nạn giao thông đển khám và điêu trị tại Bệnh viện đa khoa Sóc Trăng, Luân văn chuyên khoa cấp II, Trường Đại học Y Dược Cần Thơ.

\title{
NHẬN XÉT GIÁ TRI CỦA SIÊU ÂM TRONG CHẨN ĐOÁN VIÊM RUỘT THỪ'A CẤP Ở TRẺ EM TẠI BỆNH VIÊ̂N ĐA KHOA QUỐC TẾ HẢI PHÒNG, NĂM 2018-2020
}

\section{TÓM TẮT}

Đặt vấn đề: Nghiên cứu này nhằm mục tiêu mô tả hình ảnh và nhận xét vai trò của siêu âm trong chẩn đoán viêm ruột thừa cấp ở ở trẻ em tại Bệnh viên Đa khoa quốc tế Hải Phòng từ ngày 01 tháng 09 năm 2018 đến ngày 31 tháng 8 năm 2020. Đối tượng và phương pháp nghiên cứu: Nghiên cứu mồ tả một loạt ca bệnh bào gồm các bệnh nhân dưới 16 tuổi, có lẩm sàng nghi ngờ, có siểu âm ổ bụng chẩn đoán là VRT. Bệ̂nh nhân được điều trị bằng phẫu thuật, làm giải phẫu bệnh hoăcc được theo dõi, hoặc điều trị nội khoa đến khi ổn định. Phương pháp chọn mẫu thuận tiện bằng cách lấy toàn bộ bệnh nhân đạt đủ tiêu chuẩn nêu trên được khám và điều trị tại Bệnh

${ }^{1}$ Trường Đại học Y dược Hải Phòng; ²Bênh viện Đa khoa Quốc tế Hải Phòng Chịu trách nhiệm chính: Hoàng Đức Hạ Email: drhoangducha.hp@gmail.com Ngày nhận bài: 27.10.2021

Ngày phản biện khoa học: 20.12.2021

Ngày duyệt bài: 30.12 .2021

\section{Hoàng Đức Hạ ${ }^{1,2}$, Cao Thanh Đỗ ${ }^{1}$}

viện Đa khoa quốc tế Hải Phòng trong thời gian nghiên cứu từ $1 / 9 / 2018$ đến $31 / 8 / 2020$. Kết quả và Kết luận: Nghiên cứu gồm 90 bệnh nhi, tuổi từ 4-15 tuổi; tỷ lệ nam/nữ là 2,24/1. Siêu âm chẩn đoán đúng $100 \%$ trường hợp VRT khi ruột thừa ở vị trí bình thường và $66,7 \%$ khi ruột thừa ở vị trí bất thường. Siêu âm chẩn đoán VRT có độ nhay $97,5 \%$, độ đặc hiệu 88,8\%, giá trị dự đoán dương tính 98,7\%, giá trị dư đoán âm tính $80 \%$. Hình ảnh VRT thướng gắp là: Lòng RT đầy dịch, ấn không xẹp, đường kính ngang > $6 \mathrm{~mm}$, dày thành RT, có phản ứng đầu dò. Dấu hiêu gián tiếp có tỷ lệ cao là thâm nhiếm mõ chiếm 93,8\%. Siêu âm chẩn đoán VRT có biến chứng với độ nhạy $66,7 \%$, độ đặc hiệu 98,6\%, giá trị dự đoán dương tính $85,7 \%$, giá trị dự đoán âm tính 95,9\%.

Tư khoá: viêm ruột thừa, bệnh nhi, siêu âm

\section{SUMMARY}

EVALUATION OF THE VALUE OF ULTRASOUND IN THE DIAGNOSIS OF ACUTE APPENDICITIS IN CHILDREN AT HAI PHONG INTERNATIONAL GENERAL HOSPITAL, 2018-2020

Introduction: This study aims to describe images 
and comment on the role of ultrasound in the diagnosis of acute appendicitis in children at Hai Phong International General Hospital from September 1, 2018 to August 31, 2020. Subjects and methods: A descriptive study of a series of patients under 16 years of age, clinically suspected, and diagnosed by abdominal ultrasound as acute appendicitis. The patient was treated with surgery, pathology or monitored, or medical treatment until stable. Convenient sampling method by taking all patients who met the above criteria were examined and treated at Hai Phong International General Hospital during the study period from September 1, 2018 to August 31, 2020. Results and Conclusions: The study included 90 pediatric patients, aged 4-15 years old; The male/female ratio was 2.24/1. Ultrasound correctly diagnosed $100 \%$ of acute appendicitis when the appendix was in a normal position and $66.7 \%$ when the appendix was in an abnormal position. Ultrasound diagnosis of appendicitis had a sensitivity of $97.5 \%$, a specificity of $88.8 \%$, a positive predictive value of $98.7 \%$, a negative predictive value of $80 \%$. Common appendicitis images were: the appendix lumen was filled with fluid, not collapsed, transverse diameter $>6 \mathrm{~mm}$, RT wall thickness, probe response. Indirect sign with a high rate was fat infiltration accounting for $93.8 \%$. Ultrasound diagnosis of complicated acute appendicitis with sensitivity $66.7 \%$, specificity $98.6 \%$, positive predictive value $85.7 \%$, negative predictive value $95.9 \%$.

Keywords: appendicitis, pediatric patients, ultrasound.

\section{I. ĐĂT VẤN ĐỀ}

Viêm ruột thừa (VRT) là một cấp cứu ngoại khoa thường gặp, có bệnh cảnh lâm sàng đa dạng, có thể khó chẩn đoán ở trẻ em do khó xác định chính xác vị trí đau và triệu chứng lâm sàng phức tap, thay đổi trên mỗi bệnh nhi nên dễ nhầm lẩn với nhiều bệnh lý khác. ở trẻ em, bệnh cũng thường diễn biến nhanh nên việc chẩn đoán hay điêu trị không kịp thời dễ gây viêm phúc mạc ruột thừa (VPMRT), dẫn đên các biên chứng trầm trọng, có thể khiến trẻ tử vong. Siêu âm ố bụng là một phương pháp được chỉ định thường quy trong hầu hết bệnh nhân đau bụng, tiến hành một cách an toàn, nhanh chóng, không gây đau, không chảy máu, giá thành rẻ. Hơn nữa còn có thể thực hiênn nhiều lần khi còn nghi ngờ, mang lại giá trị chẩn đoán cao. Tại Việt Nam cũng như trên thế giới đã có một số tác giả nghiên cứu về viêm ruột thừa cấp ở trẻ em $[5,6$,
7]. Tại Hải Phòng chưa có nghiên cứu nào đánh giá đặc điểm hình ảnh và vai trò của siêu âm trong việc chẩn đoán bệnh lý viêm ruột thừa (VRT) ở trẻ em. Nghiên cứu này nhằm mục tiêu mô tả hình ảnh và nhận xét vai trò của siêu âm trong chẩn đoán viêm ruột thừa cấp ở ở trẻ em tại Bệnh viện Đa khoa quốc tế Hải Phòng từ ngày 01 tháng 09 năm 2018 đến ngày 31 tháng 8 năm 2020.

\section{II. ĐỐI TƯợNG VÀ PHƯƠNG PHÁP NGHIÊN CỨU 2.1. Đối tượng, thời gian và địa điểm nghiên cứu \\ Đối tượng nghiên cứu bao gồm các bệnh} nhân dưới 16 tuổi, có lâm sàng nghi ngờ, có siêu âm ổ bụng chẩn đoán là VRT. Bệnh nhân được điều trị bằng phẫu thuật, làm giải phẫu bệnh hoặc được theo dõi, hoặc điều trị nội khoa đến khi ổn định tại Bệnh viện ĐKQT Hải Phòng, được chẩn đoán xác định bệnh khi ra viện.

Tiêu chuẩn xác định VRT có biến chứng bao gôm ruột thừa bị viêm thủng hoặc hoại tử và ổ bụng có mủ, giả mạc. Trong trường hợp không điển hình: ruột thửa có viêm rõ rệt trên đại thể nhưng chưa thủng, có phản ứng của các quai ruột và mạc nối lớn đến bao bọc ruột thừa, ổ bụng có dịch đục, cấy dịch có vi khuẩn, có trên 500 bạch câu/ ml dịch.

Nghiên cứu được tiến hành trong thời gian từ 1/9/2018 đến 31/8/2020 tại Bệnh viện Đa khoa quốc tế Hải Phòng.

2.2. Phương pháp nghiên cứu. Nghiên cứu mô tả một loạt ca bệnh, chọn mấu theo phương pháp thuận tiện bằng cách lẩy toàn bộ bệnh nhân đạt đủ tiều chuẩn nêu trên được khám và điều trị tại Bệnh viện Đa khoa quốc tế Hải Phòng trong thời gian nghiên cứu. Mỗi bệnh nhân được ghi nhận thông tin theo một mẫu bệnh án nghiển cứu chung. Trên bệnh án ghi đầy đủ các nội dung phục vụ nghiên cứu. Toàn bộ số liệu thu thập sẽ được xử lý bằng phần mềm thống kê y học SPSS 22.0. So sánh giữa các biến liên tục bằng thuật toán kiểm định T- Student. Các biến rời rạc được trình bày dưới dạng \% và so sánh kết quả của các biến bằng thuật toán kiểm định khi bình phương $\left(x^{2}\right)$, Fisher's exact test. Sự khác biệt có ý nghĩa thống kê khi $\mathrm{p}<0,05$.

\section{KẾT QUẢ NGHIÊN CỨU}

Nghiên cứu gồm 90 bênh nhi, tuổi từ 4-15 tuổi; tỷ lê nam/nữ là 2,24/1.

Bảng 3.1. Vị trí ruột thừa trên siêu âm đôí chiếu phẫu thuật $(n=81)$

\begin{tabular}{|c|c|c|c|c|c|}
\hline Vị trí trên siêu trí trến PT & $\begin{array}{c}\text { Hố châau } \\
\text { phải }\end{array}$ & $\begin{array}{c}\text { Sau manh } \\
\text { tràng }\end{array}$ & $\begin{array}{c}\text { Tiếu } \\
\text { khung }\end{array}$ & Khác & $\begin{array}{c}\text { Tống } \\
(\mathbf{n = 8 1})\end{array}$ \\
\hline Hố chậu phải & 75 & 2 & 1 & 0 & 78 \\
\hline Sau manh tràng & 0 & 3 & 0 & 0 & 3 \\
\hline
\end{tabular}




\begin{tabular}{|c|c|c|c|c|c|}
\hline Tiếu khung & 0 & 0 & 1 & 0 & 1 \\
\hline Khác & 0 & 0 & 0 & 0 & 0 \\
\hline Tống & $\mathbf{7 5}$ & $\mathbf{5}$ & $\mathbf{1}$ & $\mathbf{0}$ & $\mathbf{8 1}$ \\
\hline
\end{tabular}

Nhận xét: Toàn bộ BN được siêu âm và đều quan sát thấy ruột thừa trên siêu âm. Khi ruột thừa ở vị trí bình thường thì siêu âm chẩn đoán đúng $100 \%$ trường hợp, ruột thừa ở vị trí bất thường thì siêu âm chẩn đoán đúng được 4/6 trường hợp đạt 66,7\%.

Bảng 3.2. Các dấu hiệu của siêu âm

\begin{tabular}{|c|c|c|}
\hline Dấu hiệu siêu âm & $\begin{array}{l}\text { Có VRT } \\
(\mathrm{n}=81)\end{array}$ & \begin{tabular}{|c|}
$\begin{array}{c}\text { Không VRT } \\
(\mathrm{n}=9)\end{array}$ \\
\end{tabular} \\
\hline & & \\
\hline Lòng RT chứa đầy dịch & $59(72,8)$ & 0 \\
\hline Lòng RT chứa sỏi phân & $19(23,3)$ & 0 \\
\hline RT ấn không xẹp & $77(95,1)$ & $2(22,2)$ \\
\hline $\begin{array}{l}\text { Đường kính ngang } \\
>6 \mathrm{~mm}\end{array}$ & $79(97,5)$ & $1(11,2)$ \\
\hline Dày thành RT & $73(90,1)$ & 0 \\
\hline Mất liên tục thành RT & $5(6,2)$ & 0 \\
\hline $\begin{array}{c}\text { Tăng tín hiệu trên } \\
\text { Doppler }\end{array}$ & $25(30,9)$ & $1(11,2)$ \\
\hline Phản ứng đầu dò & $79(97,5)$ & $2(22,2)$ \\
\hline Thâm nhiêm mõ̃ & $76(93,8)$ & $1(11,2)$ \\
\hline Hạch xung quanh & $46(56,8)$ & $2(22,2)$ \\
\hline $\begin{array}{l}\text { Dày thành hồi } \\
\text { tràng/manh tràng }\end{array}$ & $42(51,9)$ & $2(22,2)$ \\
\hline Dịch ố bụng & $13(16)$ & 0 \\
\hline
\end{tabular}

Nhận xét: Trong nhóm trẻ viêm ruột thừa, các dấu hiệu siêu âm tại ruột thừa chiểm tỷ lệ cao là: Lòng RT đầy dịch, ân không xẹp, đường kính ngang $>6 \mathrm{~mm}$, dày thành $\mathrm{RT}$, có phản ứng đầu dò. Các dấu hiệu đều chiếm > 70\% trong các trường hợp. Dấu hiệu gián tiếp có tỷ lệ cao là thâm nhiễm mõ chiếm 93,8\%.

Bảng 3.3. Giá trị chân đoán của siêu âm viêm ruột thừa cấp $(n=90)$

\begin{tabular}{|c|c|c|c|}
\hline $\begin{array}{c}\text { Kết luận } \\
\text { siêu âm }\end{array}$ & Có VRT & $\begin{array}{c}\text { Không } \\
\text { VRT }\end{array}$ & Tổng \\
\hline Có VRT & 79 & 1 & 80 \\
\hline Không VRT & 2 & 8 & 10 \\
\hline Tống & $\mathbf{8 1}$ & $\mathbf{9}$ & $\mathbf{9 0}$ \\
\hline
\end{tabular}

Nhận xét: Độ nhạy: 79/81 = 0,975 (97,5\%), độ đặc hiệu: $8 / 9=0,888(88,8 \%)$, giá trị dự đoán dương tính: $79 / 80=0,987(98,7 \%)$, giá trị dự đoán âm tính: $8 / 10=0,8(80 \%)$.

Bảng 3.4. Giá trị siêu âm chân đoán biên chứng viêm ruột thừa $(n=81)$

\begin{tabular}{|c|c|c|c|}
\hline Kết luận siêu âm & $\begin{array}{c}\text { VRT } \\
\text { có biến } \\
\text { chứng }\end{array}$ & $\begin{array}{c}\text { VRT } \\
\text { khống } \\
\text { biến } \\
\text { chứng }\end{array}$ & Tổng \\
\hline VRT có biến chứng & 6 & 1 & 7 \\
\hline VRT không biến chứng & 3 & 71 & 74 \\
\hline Tống & $\mathbf{9}$ & $\mathbf{7 2}$ & $\mathbf{8 1}$ \\
\hline
\end{tabular}

Nhận xét: Độ nhạy: $6 / 9=0,667(66,7 \%)$, độ đặc hiệu: $71 / 72=0,986(98,6 \%)$, giá trị dự đoán dương tính: $6 / 7=0,857(85,7 \%)$, giá trị dự đoán âm tính: $71 / 74=0,959(95,9 \%)$.

Bảng 3.5. Giá trị siêu âm kết hợp với thang điêm PAS $(n=90)$

\begin{tabular}{|c|c|c|c|}
\hline $\begin{array}{c}\text { Chấn đoán kết } \\
\text { hợp }\end{array}$ & $\begin{array}{c}\text { Có } \\
\text { VRT }\end{array}$ & $\begin{array}{c}\text { Không } \\
\text { VRT }\end{array}$ & Tổng \\
\hline Có VRT & 80 & 3 & 83 \\
\hline Không VRT & 1 & 6 & 7 \\
\hline Tống & $\mathbf{8 1}$ & $\mathbf{9}$ & $\mathbf{9 0}$ \\
\hline
\end{tabular}

Nhận xét: Độ nhạy: 80/81 = 0,987 (98,7\%), Độ đặc hiệu: $6 / 9=0,667(66,7 \%)$, Giá trị dự đoán dương tính: $80 / 83=0,964(96,4 \%)$, Giá trị dự đoán âm tính: $6 / 7=0,857$ (85,7\%).

\section{BÀN LUẬN}

Về xác định vị trí ruột thừa trên siêu âm: Theo kết quả nghiên cứu thì tất cả bệnh nhân khi siêu âm đều được quan sát thấy ruột thừa. Ruột thừa ở vị trí bình thường trên siêu âm là $95,6 \%$, sau manh tràng là $3,3 \%$ và $1,1 \%$ ở trong tiểu khung. Kết quả lần lượt trên phẫu thuật là $92,6 \%, 6,2 \%$ và $1,2 \%$. Kết quả nghiên cứu này tương đương với tác giả Dương Văn Mai [4] khi thấy $95,1 \% \mathrm{RT}$ ở HCP, 3,7\% sau manh tràng và $1,2 \%$ vị trí khác. Bùi Đức Hậu (2015) [2] khi nghiên cứu 216 bệnh nhi thây $86,6 \%$ vị trí RT bình thường, $10 \%$ sau manh tràng và $3,4 \%$ RT nằm các vị trí khác. Phan Thanh Lương và Trần Ngọc Bích thấy RT ở vị trí bình thường là $80,6 \%$, $10,1 \%$ sau manh tràng và $9,3 \%$ ở các vị trí khác khi nghiên cứu 268 trẻ em VRTC [3]. Nguyễn Thị Minh Chính thấy rằng tới 20,4\% RT ở vị trí bất thường ở trẻ nhỏ [1], cao hơn nghiên cứu của chúng tôi. Các kết quả chưa đồng nhất cho thấy rằng vị trí của RT ở đối tượng trẻ em là rất đa dang, phức tạp nên dễ gây những nhầm lẫn, sai sót. Trường hợp ruột thừa đúng vị trí bình thường có thể thấy rằng siêu âm chẩn đoán chính xác vị trí đạt $100 \%$, vị trí bất thường thì siêu âm chỉ chẩn đoán đúng $66,7 \%$ trường hợp.

Đánh giá hình thái ruột thừa viêm: Trong nghiên cứu của chúng tôi, đường kính ngang của ruột thừa chỗ lớn nhất $>6 \mathrm{~mm}$ chiếm đến $95,1 \%$ trẻ VRT, đường kính trung bình $8,97 \pm 3,02 \mathrm{~mm}$ ). Ruột thừa viêm có đường kính ngắn nhất là $3,9 \mathrm{~mm}$ và lớn nhất là một trường hợp có đường kính ngang chỗ lớn nhất lên đến $25 \mathrm{~mm}$. Đó là trường hợp bệnh nhân đến khám ở thời điểm 
ngày thứ 3, trong lòng RT chứa sỏi phân nhưng RT chưa vơ.

Thành ruột thừa: Thành ruột thừa có liên quan mật thiểt đến đường kính ruột thừa. Bình thường thành $\mathrm{RT}$ từ 1-2 mm, ruột thừa viêm có thành dày $>2 \mathrm{~mm}$. Trong nghiên cứu của chúng tôi có tới $90,1 \%$ trường hợp dày thành ruột thừa khi viêm, có $6,2 \%$ trường hợp mất liên tục có giá trị gợi ý đến thủng ruột thừa. 30,6\% trường hợp VRT có tăng tín hiệu mạch trên doppler, không đặc hiệu nhưng có giá trị khi kết hợp với các dấu hiệu khác.

Lòng ruột thừa: Bình thường, trong lòng ruột thừa chứa khí. Khi lòng ruột thừa bị bít tắc, khí sẽ không thông được qua van Gerlach, dịch viêm được tiết vào lòng ruột thừa làm ruột thừa căng to. Trong nghiên cứu của chúng tôi có $72,8 \%$ trường hợp lòng ruột thừa căng đầy dịch. Sỏi phân có trong 23,3\% trường hợp, đây là dấu hiệu gợi ý cao đến VRT do sỏi phân thường sẽ gây bít tắc lòng ruột thừa.

Đánh giá dấu hiệu gián tiếp của ruột thừa viêm: Dấu hiệu gián tiếp đóng vai trò nhất định trong việc chẩn đoán VRT. Estey $A$ và cộng sự nhận định độ đặc hiệu của dấu hiệu thâm nhiếm mõ là $98 \%$, hạch xung quanh là $81 \%$ và dịch ổ bụng là $98 \%$ [9]. Trong nghiên cứu của chúng tôi có $93,8 \%$ trường hợp thâm nhiễm mõ quanh ruột thửa, có $97,5 \%$ bệnh nhân đau khi ấn đầu dò vào điểm ruột thừa, hạch xung quanh gặp trong 56,8\% trường hợp, 51,9\% trường hợp dày thành manh tràng và $16 \%$ có dịch ổ bụng. Các dấu hiệu gián tiếp thường có giá trị khi đi kèm với các dấu hiệu trực tiếp. Trong trường hợp không thấy ruột thừa thì các dấu hiệu này gợi ý chẩn đoán VRT. Kết quả tương đồng với một số tác giả.

Vê giá trị siêu âm trong chẩn đoán viêm ruột thừa: Siêu âm được nghiên cứu và đạt được vị trí quan trọng trong các phương pháp chẩn đoán VRT.

Trong nghiên cứu của chúng tôi, toàn bộ bệnh nhân được tiến hành siêu âm ổ bụng và $100 \%$ đều thấy được hình ảnh của RT. Kết quả nghiên cứu cho thây $80 / 90$ bệnh nhân được siêu âm chẩn đoán viêm ruột thừa trong đó trùng với chẩn đoán sau cùng là $79 / 81$ bệnh nhân đạt $97,5 \%$. Môtt trường hợp siêu âm thấy đường kính ngang chổ lớn nhất của RT là $6,2 \mathrm{~mm}$, có thâm nhiễm mõ , dày thành manh tràng và tăng tín hiệu doppler mạch nhưng trên lâm sàng không điển hình, điểm PAS dưới 7, bệnh nhân được chụp $\mathrm{CT}$ thây hình ảnh viêm manh tràng. Bênh nhẩn không phẫu thuật, được điều trị nội khoa 7 ngày, ra viện trong tình trạng ổn định.

Có hai bệnh nhân siêu âm chẩn đoán không viêm ruột thừa. Một bệnh nhân có đường kính ngang ruột thừa dưới $6 \mathrm{~cm}$, thành không dày, không có dấu hiệu gián tiếp khác, được chụp CT cho kết quả tương tự nhưng trên lâm sàng triệu chứng khá rõ ràng ${ }_{\ell}$ điểm PAS trên 7 , bệnh nhẩn được hội chẩn phấu thuật, làm giải phẫu bênh thấy ruột thừa viêm xung huyết. Đây là trường hợp bệnh nhân đễn khám sớm, thời điểm RT sung huyết nhẹ, do phản ứng đáp ứng viêm toàn thân mạnh và cũng có thể ngưỡng đau của bệnh nhân kém nên biểu hiện rầm rộ trên lâm sàng. Một bệnh nhân còn lại siêu âm thấy kích thước $\mathrm{RT}<6 \mathrm{~cm}$, thành bình thường, không có dấu hiệu khác kèm theo, điểm PAS dưới 7 điểm. Bệnh nhân được theo dõi, sau đó được chụp CT ổ bụng thấy hình ảnh viêm ruột thửa, bệnh nhân được phẫu thuật và làm giải phẫu bệnh kết quả là viêm ruột thừa mủ. Trường hợp này bệnh nhân cũng đến sớm, ruột thừa kích thước dài, viêm ở đầu tự do, siêu âm không quan sát hết được. Kết quả nghiên cứu của chúng tôi thấy rằng siêu âm có độ nhạy $97,5 \%$, độ đặc hiệu $88,8 \%$. Kết quả tương đương với một số tác giả trong và ngoài nước [7].

Trong chẩn đoán biến chứng của VRT, giá trị độ nhạy của siêu âm còn chưa được cao, chỉ đạt $66,7 \%$, độ đặc hiệu tốt hơn là $98,6 \%$. Kết quả này tương đương với tác giả Gonzalez DO với kết quả lần lượt là $42,2 \%$ và $90,4 \%$ hay tác giả Carpenter JL với kết quả tương ứng là $44,0 \%$ và $93,1[8]$. Trần Kiến Hào và cộng sự (2020) thấy kết quả lần lượt là $23,5 \%$ và $95,4 \%$. Do trong những trường hợp VRT có biến chứng thì bệnh nhân đau nhiêu, hợp tác kém, kích thước thành ruột thừa chỉ vài $\mathrm{mm}$ nên việc xác định tính mất liên tục không được rõ ràng. Bên cạnh đó khi VRT có biến chứng thì phản ứng của các tổ chức xung quanh tương đối mạnh mẽ, quây đến bao bọc ruột thừa làm che đi các đă̆c điểm của ruột thừa, cùng với các yếu tố nhiểu khác gây ảnh hưởng đến kỹ thuật siêu âm.

\section{KẾT LUÂN}

Các dấu hiệu siêu âm thường gặp trên trẻ có VRT: đường kính ngang chỗ lớn nhất > $6 \mathrm{~mm}$, thành ruột thừa dày, lòng ruột thừa căng dịch, ấn không xẹp, có phản ứng đầu dò và thâm nhiễm mõ quanh ruột thừa. Siêu âm có giá trị cao trong chẩn đoán viêm ruột thừa với độ nhạy 97,5\%; độ đặc hiệu 88,8\%; giá trị dự đoán dương tính 98,7\%; giá trị dự đoán âm tính $80 \%$. Trong đánh giá biến chứng của VRT, siêu âm có 
độ nhạy 66,7\%; độ đặc hiệu 98,6\%; giá trị dự đoán dương tính 85,7\%; giá trị dự báo âm tính: 95,9\%. Khi kết hợp với thang điểm chẩn đoán viêm ruột thừa ở trẻ em (PAS), sẽ nâng cao hơn nữa hiệu quả của siêu âm trong chẩn đoán viêm ruột thừa.

\section{TÀI LIÊU THAM KHẢO}

1. Nguyễn Thi Minh Chính (2012). Nghiên cứu đặc điểm lâm sàng, cận lâm sàng viêm ruột thửa trẻ em dưới 5 tuô̂i. Luận án bác sĩ chuyên khoa cấp II, Trường đại học Y Hà Nội, Hà Nô̂i.

2. Bùi Đức Hậu (2015). Viêm ruột thừa trẻ em: Lâm sàng, cận lấm sàng và kết quả điêu trị. Tạp chí y hoc Viêt Nam. 2(420): 51-56.

3. Phan Thanh Lương, Trân Ngọc Bích, Vũ Huy Nùng (2003). Nghiên cứu đắc điểm lâm sàng cận lấm sàng và giải phẫu bệnh lý trong viêm ruột thừa cấp ở trẻ em. Tạp chí Y học thực hành. 2: 27-32.
4. Dương Văn Mai (2016). Nghiên cứu kết quả điều trị viêm ruột thừa cấp ở trẻ em bằng phẩu thuật nôi soi tai bênh viên đa khoa tỉnh Phú Tho. Luận vắn bác sĩ nội trú, Đ̇ại học Y dược Thái Nguyên.

5. Pham Thị Minh Rang, Pham îê An (2012). Giá trị thang điểm Alvarado và siêu âm trong chẩn đoán viểm ruột thừa cấp ở trẻ em. Nghiên cứu y hoc. 16(1): 96-101.

6. Almaramhy HH (2017). Acute appendicitis in young children less than 5 years: review article. Ital J Pediatr. 43(1): 15.

8. Carpenter JL, Orth RC, Zhang $W$ et al (2017). Diagnostic Performance of US for Differentiating Perforated from Nonperforated Pediatric Appendicitis: A Prospective Cohort Study. Radiology. 282(3): 833-841.

9. Estey A, Poonai N, Lim R (2013). Appendix not seen: the predictive value of secondary inflammatory sonographic signs. Pediatr Emerg Care. 29(4): 435-439.

\section{SỰ ẢNH HƯởNG CỦA KÍCH THƯớC VÀ TỶ LÊ TẢI TRÊN SỰ GIẢI PHÓNG DƯợC CHẤT CỦA VI CÂUU XỐP CHỨ METRONIDAZOL}

\section{TÓM TẮT}

Muc tiêu: Thiết lập các thông số điêu chế phù hợp để tạo ra các vi cầu xốp chứa dược chất metronidazol có đắc tính kích thước và tỉ lế tải khác nhau. Từ đó, khảo sát ảnh hưởng của các đặc tính này đến khả năng kiểm soát sự giải phóng và động học giải phóng dược chất từ vi câu xốp. Đối tượng và phương pháp: Vi câu xốp ethyl cellulose chứa metronidazol là đối tượng của nghiên cứu. Vi cầu được điều chế bằng phương pháp bốc hơi dung môi từ nhũ tương. Các đặc tính của vi cầu được nghiên cứu là kích thước trung bình, tỷ lệ tải sự ảnh hưởng của chúng trên khả năng và động học giải phóng dược chất. Kết quả: Kích thước và tỷ lệ tải của vi cầu tạo thành có thể được kiểm soát thông qua nồng độ ethyl cellulose, nồng độ dược chất phân tán trong pha dâu, nồng đố chất ổn đinh nhũ tương hoăc các thông số quy trình như tốc độ và thời gian đồng nhất hóa. Vi câu có kích thước lớn hơn, tỷ lệ tải cao hơn cho thây khả năng giải phóng dược chất nhanh hơn. Dược chất được giải phóng khỏi vi cầu nhờ cơ chế khuếch tán kết hợp với sự bào mòn của chuỗi polyme. Kết luận: Kích thước và tỷ lệ tải của vi câu xốp ethyl cellulose có thể được kiểm soát thông qua các thông số điều chế và từ đó có thể giúp kiểm soát khả năng giải phóng dược chất của vi cầu. Tư khóa: vi câu xốp ethyl cellulose, metronidazole, giải phóng dược chất

${ }^{1}$ Dại học Y Dược Tp. Hồ Chí Minh

Chịu trách nhiệm chính: Lê Minh Quân

Email: leminhquan@ump.edu.vn

Ngày nhận bài: 1.11.2021

Ngày phản biện khoa học: 27.12.2021

Ngày duyệt bài: 4.01.2022
Lê Minh Quân ${ }^{1}$, Tiêu Du Trương ${ }^{1}$, Lê Hậu ${ }^{1}$

\section{SUMMARY}

EFFECT OF PARTICLE MEAN SIZE AND

ENCAPSULATION RATIO ON THE DRUG

RELEASE OF METRONIDAZOLE-LOADED

POROUS MICROSPHERE

Objective: Formulate various porous microsphere batches with different particle mean sizes and encapsulation ratios. Those microspheres would be employed to investigate the effect of the spheres' characteristics on their drug release. Subjects and methods: Porous ethylcellulose-based microspheres containing metronidazole were studied. The microspheres were prepared by emulsification solvent evaporation method. The spheres' mean size and encapsulation ratios and their effects on drug release rates and kinetics would be focused on. Results: The resultant microspheres' size and drug loading ratio could be controlled through polymer concentration, drug concentration in the oil phase, emulsion stabilizer concentration or process parameters such as homogenization speed and time. Microspheres with a larger size or higher loading ratio presented faster drug release. Drugs are released from microspheres by a diffusion mechanism combined with polymer chain erosion. Conclusion: The size and drug encapsulation ratio of ethyl cellulose-based porous microspheres could be controlled through parameter modulation and could help control the drug release profile of the microspheres.

Keywords: porous microsphere ethyl cellulose, metronidazole, drug release

I. ĐẶT VẤN ĐỀ

Vi cầu (microsphere) là các tiểu phân hình 